lengths of 5577 and $6300 \AA$., respectively. Photometric apparatus installed for use during the International Geophysical Year has been improved, and observations on these lines have been resumed. While the telescope used for this work normally points to the south at a zenith angle of $80^{\circ}$, it can quickly be changed to an all-sky survey when required to observe aurora.

Observations of geomagnetic micropulsations have been made during the year at Camdon and Adelaide, by means of a large horizontal loop of wire buried in the ground and connected to a galvanometer-photocell amplifier. The pulsations are recorded on paper charts or on magnetic tapes, the latter having the advantage that they may be replayed at such a speed that the oscillations are in the audio-frequency range which facilitates their analysis. The most common frequencies of these pulsations observed at Hobart, Adelaide and Townsville were 1.3, 2.5 and $3 \mathrm{c} . / \mathrm{min}$., respectively. They exist for periods which show a diurnal variation; at Adelaide, for example, the period varies smoothly from about 15 sec. at $0600 \mathrm{hr}$. to 24 sec. at midday.

During magnetically disturbed periods, it has been found that the frequency of the pulsations may sweep over a range of 1-32 c./min., at a rate of approximately $1 \mathrm{c} . / \mathrm{min} . / \mathrm{min}$. Although swept frequency micropulsations have previously been observed in other countries, these have been at frequencies of about $2 \mathrm{c} . / \mathrm{s}$. The low-frequency events recorded above do not appear to have been noticed before.

\title{
THE BRITISH BOOT, SHOE AND ALLIED TRADES RESEARCH ASSOCIATION
}

$\mathrm{T}$ WELVE years ago Nature published an article on the British Boot, Shoe and Allied Trades Research Association (SATRA) (Nature, 164, 871; 1949), on the occasion of the opening of new labora. tories at Satra House, Kettering, by H.R.H. Duke of Gloucester. The Association was then in the throes of its post-war re-organization and the article proudly proclaimed "to-day the whole of the shoe industry of Great Britain is connected with the Research Association either in full membership or affiliation".

The intervening twelve years have been a period of vigorous activity in various sections of the Association's programme and the grip of the Association on its industry has strengthened; the usefulness of the Association and the practical application of its recommendations have interpenetrated the whole industry so that to-day it can be asserted with confidence that this Research Association is thoroughly integrated with its industry and accepted without question as essential to the industry's well-being in this scientific era. The present article follows a recent visit to the Association made by $\mathrm{Mr}$. Denzil Freeth, Parliamentary Secretary to the Minister for Science, who was much impressed by all that he saw.

The research association concept as understood at Satra is that a research association should mature to become the spearhead of its industry's drive into the future, to give the lead and to be an implement for the enhancement of the industry's progressiveness. It must therefore itself be an exemplar of progressiveness and any activity which is definitely conducive to progressiveness in the industry comes reasonably within the research association's scope.

For the attainment of this concept experience shows that, at any rate for small-firm craft-based industry, the research association must be a tripartite organization with a kind of equivalence of strength between the parts, which are: the industry, the public (Government), and the staff. All these must be present in strength; without the industry the association would obviously be a Government research station; without the Government it would be just a trade association; with both industry and Government the staff can be strong in purpose, cerving a cause, and gaining confidence and stature in their national status. A research association is thus a stable tripod with three strong legs, and any serious weakening of any one of the legs means departure from the perfect research association as here conconceived.

Policy and programmes of research are of course in consonance with this structure and at Satra they embrace practical work on factory productivities, operational research, ergonomics; work for the improvements of the product, consumer satisfaction, and for the public good; basic research in the science of materials and the fringe sciences of bio-mechanics and bio-physics. All parts of the programme are planned to afford scope to research workers of highest calibre.

Satra's achievements can conveniently be grouped into three sections: materials, manufacture and the product.

The shoe-manufacturing industry buys its materials and components to a total of something of the order of $£ 100,000,000$ per year. The Research Association's contribution is to minimize waste in this expenditure by establishing quality targets, grades and specifications to guide the supplying industries in their development work and to guide also the shoe factory personnel in their purchasing appropriately to their product. The supply industries total approximately one-half of the Research Association's membership and they work very closely indeed with Satra.

The past twelve years have witnessed an enormous expansion in variety in shoe materials concurrently with the growth of the chemical and synthetic industries, and the smoothness with which the new materials, and the new shoe-making methods associated with them, have been absorbed into the industry without the wasteful losses of old-time trial-anderror methods is legitimately to be regarded as one of this Association's great achievements.

The Association has had conspicuous success in its contribution to the efficiency of shoe factories and management techniques. Twelve years ago the Association had initiated inter-firm comparison work on productivities; later, the work expanded under the heading 'ergonomics' to include the various aspects of work study, operative training, production planning and work loading and many case-studies of factory re-organization. There have also been very important contributions from physics research with 
respect to speeding throughput and diminishing work in progress by the design of equipment to give appropriate physical treatment to the goods in work. At the same time physics has also given important guidance with respect to necessary test performance requisite in materials for some of the newer methods of shoe manufacture.

All these combine to enhance productivity and improve the quality of the product: as illustration, figures for a group of firms in the Association's membership covering 80,000 workpeople show 30 per cent productivity increase over the past ten yoars in pairages per employee.

Improvement in the product is for the public good. Special illustrations of the Association's work are to be found in children's shoes, in industrial footwear, including safety boots and shoes, in H.M. Services footwear and in special footwear for expeditions (for example, high-altitude Everest boot, and boots worn in Antarctica in the Geophysical Year).

The Association's work on children's footwear, started soon after the close of the Second World War, has spread throughout the United Kingdom and has its impact on health authorities, school authorities, clinies and welfare work of all kinds throughout the whole country and the Satra Approved Last Scheme operates everywhere. The Association operates the 'Kite' mark scheme on safety boots and shoes with the British Standards Institution. Work on service footwear is done on contracts with the War Office and with the Royal Air Force.

The earliest crafts came into being to meet the primary needs of human life for food, clothing and shelter, and footwear was in at the beginning. The essential purposes are health, comfort, protection and resthetic satisfaction. Basic science of boots and shoes therefore contains a 'bio' element-biomechanics, bio-physics, physiology and anthropometry. The work at Satra House in this basic field continues, but admittedly with fluctuating intensity. It is restricted by more urgent demands from other directions and also by problems of staff recruitment. The importance of this basic work and the need to extend belief in it throughout the industry and also through to the public is a constant spur to further effort.

H. BR.ADLEY

\section{SEAWEED TECHNOLOGY}

$\mathrm{T}$ HE fourth International Seaweed Symposium was held at Biarritz, during September 18-25, and was attended by more than 220 scientists and industrialists from thirty-four countries. In his opening address, Prof. Maurice Fontaine, directeur de l'Institut Oceanographique, extended a cordial welcome to the delegates.

At the opening session, the inaugural address was given by Dr. E. E. Percival (Scotland), who compared the polysaccharides synthesized by marine algae with those of the higher plants. Whereas many similarities between the two exist, the major difference lies in the fact that all seaweeds synthesize at least one polysaccharide containing ester sulphate groups. The brown seaweed polysaccharides, alginic acid, focoidin, and laminarin have few similarities with those of other groups of plants. The red algae synthesize mainly 1,3-linked galactans, a tendency also shown by the higher plants; but there the resemblance ends. The algal polymers also contain varying proportions of 1,4-linked 3,6-anhydro-Dand -L-galactose and sulphate groups. Starch-type polysaccharides, xylans and mannans have been isolated from different species of red and green weeds. Laminarin-type molecules have also been detected in the green algae. The major polysaccharides of these latter weeds, however, appear to fall into two groups which closely resemble, except for the presence of ester sulphate, either the plant gums or the hemicelluloses of land plants. Dr. Percival emphasized, however, that structural studies in this vast field of natural products, particularly in the Chlorophyceae, are still in their infancy, and it is probable that many differences in the fine structure of these complex molecules will emerge on further investigations. Dr. L. Provasoli (United States) reviewed recent progress in the culture of bacteria-free marine algac.

The various interests in algology, algal chemistry and seaweed utilization were all evident at this Symposium, but, in contrast with previous symposia, the botanical section was unusually well ropresented. In fact, almost two-thirds of the papers presented were on taxonomy and the culture of algae or their distribution, while the other papers were almost equally divided between pure chemistry and the various facets of the industrial utilization of seaweeds.

Critical observations on the taxonomy, growth and ecology of the marine algae ranged from a paper by Dr. P. S. Dixon (England), which suggested the disposition of the carpogonium might prove valuable in the sub-division of the Florideae, to Dr. W. J. North's (United States) account of the successful transplantation of Macrocystis pyrifera, which included a detailed account of the successful establishment in the ocean of plants raised from spores in the laboratory. Other investigations on the photosynthesis, physiology and growth of $M$. pyrifera by Dr. K. A. Glendinning (United States) suggest that this commercially important alga is perhaps the most widely studied of all the algae.

The genus Porphyra is also widely studied by both botanists and chemists. Dr. E. Conway (Scotland), in an account of her work on the growth and reproduction of $P$. linearis and $P$. umbilicalis, directed attention to the similarities and differences in the reproduction of these algae, and Dr. T. Fujiware (Japan) reported on her chemical investigation of the water-soluble red pigment, phycoerythrin, from the alga $P$. tenera. A further account of the sugar sulphates isolated from the mucilage of $P$. umbilicalis was given by Dr. J. R. Turvey (Wales). The predominant unit containing sulphate is L-galactose-6. sulphate, but several disaccharide sulphates have now been obtained and separated and two types of sulphate ester have been isolated. In each case the sulphate was attached at carbon (6) of an $x$-galactose residue, but one group contained $\mathrm{D}$-galactose and the other 6-O-methyl-D-galactose. In some of these compounds the sulphate ester group was attached to the reducing sugar unit, whereas in others it was attached to the non-reducing sugar unit.

The work being carried out in the Chemistry Department of the University of Edinburgh on the green algae was summarized by Dr. D. J. Manners 